\title{
Tinjauan pustaka \\ Penilaian Kesadaran pada Anak Sakit Kritis: Glasgow Coma Scale atau Full Outline of UnResponsiveness score?
}

\author{
Rismala Dewi \\ Departemen Ilmu Kesehatan Anak Fakultas Kedokteran Universitas Indonesia/ RS Dr. Cipto Mangunkusumo, Jakarta
}

\begin{abstract}
Pemeriksaan neurologis tingkat kesadaran sangat penting untuk menilai secara komprehensif pasien anak sakit kritis, dan dapat memberikan informasi prognosis. Skala koma yang ideal seharusnya bersifat linear, reliabel, valid, dan mudah digunakan. Berbagai macam skala koma telah dikembangkan dan di validasi untuk mengevaluasi tingkat kesadaran secara cepat, menilai beratnya penyakit dan prognosis terhadap morbiditas dan mortalitas. Glasgow Coma Scale (GCS) merupakan alat pemeriksaan tingkat kesadaran yang paling sering digunakan dan dijadikan baku emas saat memvalidasi skala koma yang baru. GCS mempunyai keterbatasan karena pasien yang terintubasi tidak dapat dinilai komponen verbal sehingga memengaruhi hasil penilaian. FOUR Score dikembangkan untuk mengatasi berbagai keterbatasan yang dimiliki GCS. FOUR score lebih sederhana dan memberikan informasi yang lebih baik, terutama pada pasien-pasien yang terintubasi. Sari Pediatri 2016;17(5):401-6.
\end{abstract}

Kata kunci: Glasgow Coma Scale, Full Outline of UnResponsiveness score, anak sakit kritis

\section{Review article}

\section{Assessment of Consciousness in Critically Ill Children: Glasgow Coma Scale or Full Outline of UnResponsiveness Score?}

Rismala Dewi

Neurological evaluation of level of consciousness is very important to assess comprehensively in critically ill children, and may provide prognostic information. An ideal coma scale would be linear, reliable, valid, and easy to use. Various kinds of coma scale were developed and validated to rapidly evaluate level of consciousness, assess the severity of the disease and prognosis for morbidity and mortality. Glasgow Coma Scale (GCS) has remained as "gold standard" for assessing impaired consciousness, and it is frequently used to validate new coma scales. However, GCS has several shortcomings due to limitation to assess verbal component of intubated patients, thus may affect the results. FOUR Score was developed to overcome those limitations. Compared to GCS, FOUR score is simpler and provide better information, especially in intubated patients. Sari Pediatri 2016;17(5):401-6.

Keywords: Glasgow Coma Scale, Full Outline of UnResponsiveness score, critically ill children

\footnotetext{
Alamat korespondensi: DR. dr. Rismala Dewi, Sp.A(K).Departemen Ilmu Kesehatan Anak FKUI/RSCM. Jl. Diponegoro 71 Jakarta. Tel. +62213907742 Fax.:+62213907743. E-mail: dewi@idai.or.id, dewi_sumitro@yahoo.com
} 
T ingkat kesadaran merupakan salah satu pemeriksaan neurologis yang sangat penting untuk menilai secara komprehensif pasien anak sakit kritis, dan dapat memberikan informasi prognosis. Dengan mengetahui prediksi prognosis maka penanganan pasien menjadi lebih optimal dan motivasi untuk menangani secara maksimal lebih tinggi pada pasien dengan prognosis baik. Penilaian kesadaran merupakan keterampilan klinis yang harus dipunyai seorang dokter, walaupun definisi yang tepat untuk mendeskripsikan setiap tingkat kesadaran sulit untuk ditetapkan. ${ }^{1}$

Skala koma yang ideal seharusnya bersifat linear (mempunyai bobot yang sama bagi setiap komponen), reliabel (mengukur yang seharusnya diukur), valid (menghasilkan nilai yang sama pada pemeriksaan berulang), dan mudah digunakan (memiliki instruksi yang sederhana tanpa memerlukan alat bantu atau kartu). Skala ini seharusnya dapat juga memprediksi luaran walaupun angka kematian di ruang rawat intensif dapat dipengaruhi oleh berbagai faktor lain yang mempengaruhi. ${ }^{2}$ Sampai saat ini berbagai skala koma telah dikembangkan untuk memperbaiki komunikasi antar praktisi medis, dan standarisasi pemeriksaan pasien dengan penurunan kesadaran. ${ }^{3}$

\section{Glasgow Coma Scale (GCS)}

Skala koma pertama kali digunakan di unit perawatan intensif bedah saraf. Teasdale dan Jennet dari Institute of neurogical science Glasgow (1974) mempublikasikan indeks koma yang kemudian berganti nama menjadi GCS. Sejak dipublikasikan pertama kali, GCS menjadi skala yang paling sering digunakan tidak hanya di kalangan spesialis saraf atau bedah saraf tetapi di luar bidang tersebut, walaupun memiliki beberapa keterbatasan. ${ }^{1,3}$

Pertama, ada kecenderungan penilaian GCS lebih besar pada komponen motorik (skor 6) dibandingkan komponen verbal dan mata (skor 5 dan 4). Kedua, sebagian besar pasien yang mengalami koma terintubasi, sehingga komponen verbal tidak dapat dinilai dan kurang berguna pada 20-48\% pasien. Demikian juga pada pasien yang mengalami afasia, komponen verbal tidak dapat menilai sehingga memengaruhi hasil akhir. GCS hanya menilai orientasi, yang dengan mudah menjadi abnormal pada pasien yang mengalami agitasi dan delirium. Ketiga, GCS tidak memiliki indikator klinis seperti refleks batang otak abnormal, perubahan pola napas, dan kebutuhan akan ventilasi mekanik yang dapat mencerminkan beratnya koma. Keempat, GCS tidak mampu mendeteksi perubahan minimal pemeriksaan neurologis. Penggunaan sedasi pada sebagian besar pasien-pasien di ruang intensif juga dapat mempengaruhi ketiga komponen GCS. ${ }^{3-5}$

Sampai saat ini, GCS masih menjadi baku emas penilaian kesadaran pada semua populasi pasien. Sejumlah penelitian dilakukan untuk melakukan validasi atau usaha untuk memodifikasi skala ini dengan mengeliminasi respon mata dan verbal. Usahausaha sebelumnya yang dilakukan untuk memodifikasi ataupun menggantikan skala ini seringkali gagal karena belum ada skala yang dianggap cukup sederhana dan praktis dalam penggunaannya. ${ }^{3,6}$

\section{Komponen penilaian pada GCS}

Pada GCS terdapat 3 komponen yaitu pergerakan bola mata, verbal, dan pergerakan motorik yang dinilai dengan memberikan skor pada masing-masing komponen. Nilai total dari ketiga komponen berkisar antara 3-15, dengan nilai makin kecil semakin buruk prognosisnya. Pada pasien dengan cedera otak dapat di klasifikasikan sebagai ringan (skor GCS 14-15), sedang (skor GCS 9-13) dan berat (skor GCS $\leq 8$ ). Selain mudah dilakukan, GCS juga memiliki peranan penting dalam memprediksi risiko kematian di awal pemeriksaan. GCS dapat digunakan sebagai prediksi untuk menentukan prognosis jangka panjang dengan sensitivitas $79-97 \%$ dan spesifisitas $84-97 \%$. $^{7}$ Tabel 1 menunjukkan gambaran penilaian GCS yang dimodifikasi untuk anak. ${ }^{8,9}$

\section{Full outline of unresponsiveness (FOUR) Score}

FOUR Score dikembangkan untuk mengatasi berbagai keterbatasan yang dimiliki GCS. Skala ini memberikan lebih banyak informasi dengan adanya empat komponen penilaian: refleks batang otak, penilaian mata, respon motorik dengan spektrum luas, pola napas abnormal serta usaha napas pada pasien yang memakai ventilator, dengan skala penilaian 0-4 untuk masing-masing komponen (Tabel 2 dan Gambar 1). ${ }^{10}$ 
FOUR score dianggap lebih baik dibandingkan dengan skala-skala yang telah ada sebelumnya dalam mengklasifikasikan penurunan kesadaran. ${ }^{4,11}$ FOUR score lebih sederhana dan memberikan informasi yang lebih baik, terutama pada pasien-pasien yang terintubasi. ${ }^{2,10}$ Skala ini dapat membantu klinisi untuk bertindak lebih cepat atas perubahan klinis pasien dan memudahkan dalam pertukaran informasi yang lebih akurat dengan klinisi lain. ${ }^{11}$

Kelebihan lain dari FOUR score adalah tetap

Tabel 1. Glasgow coma scale pediatrik ${ }^{8,9}$

\begin{tabular}{lll}
\hline Kategori & Rincian & Nilai \\
\hline Respons membuka mata & Spontan & 4 \\
& Dengan perintah verbal & 3 \\
& Dengan nyeri & 2 \\
Respon motorik & Tidak ada respons & 1 \\
& Menurut perintah & 6 \\
& Dapat melokalisasi nyeri & 5 \\
Fleksi terhadap nyeri & 4 \\
Respon verbal & Fleksi abnormal & 3 \\
& Ekstensi & 2 \\
& Tidak ada respons & 1 \\
& Orientasi baik, mengoceh & 5 \\
& Iritabel, menangis & 4 \\
& Menangis dengan nyeri & 3 \\
& Mengerang dengan nyeri & 2 \\
& Tidak ada respons & 1 \\
\hline
\end{tabular}

Tabel 2. FOUR Score ${ }^{10}$

\begin{tabular}{llc}
\hline Kategori & Rincian & Nilai \\
\hline Respons mata & Kelopak mata terbuka atau pernah terbuka dan mengikuti arah atau berkedip oleh & 4 \\
& perintah & \\
& Kelopak mata terbuka namun tidak mengikuti arah & 3 \\
& Kelopak mata tertutup namun terbuka jika mendengar suara keras & 2 \\
& Kelopak mata tertutup namun terbuka oleh rangsang nyeri & 1 \\
& Jika kelopak tetap tertutup dengan rangsang nyeri & 0 \\
Respons motorik & Ibu jari terangkat atau mengepal, atau membentuk tanda 'damai' (peace sign) & 4 \\
& Melokalisir nyeri & 3 \\
& Memberi respons fleksi pada rangsang nyeri & 2 \\
& Respons ekstensi & 1 \\
Tidak ada respons terhadap nyeri atau status mioklonus umum & 0 \\
Respons batang otak & Terdapat refleks pupil dan kornea & 4 \\
& Salah satu pupil melebar terus menerus & 3 \\
& Tidak ada refleks pupil atau kornea & 2 \\
& Tidak ada refleks pupil dan kornea & 1 \\
& Tidak ada refleks pupil, kornea, atau batuk & 0 \\
Pola napas reguler, tidak terintubasi & 4 \\
& Pola Cheyne-Stokes, tidak terintubasi & 3 \\
& Pola napas iregular, tidak terintubasi & 2 \\
Respirasi & Napas dengan kecepatan di atas ventilator, terintubasi & 1 \\
& Apnea atau pernapasan dengan kecepatan ventilator, terintubasi & 0 \\
\hline
\end{tabular}


dapat digunakan pada pasien-pasien dengan gangguan metabolik akut, syok, atau kerusakan otak nonstruktural lain karena skala ini dapat mendeteksi perubahan kesadaran lebih dini. ${ }^{2}$ Dengan rentang skala penilaian yang sama di tiap-tiap komponen yakni 0-4, maka menjadi lebih mudah diingat. ${ }^{2,13}$
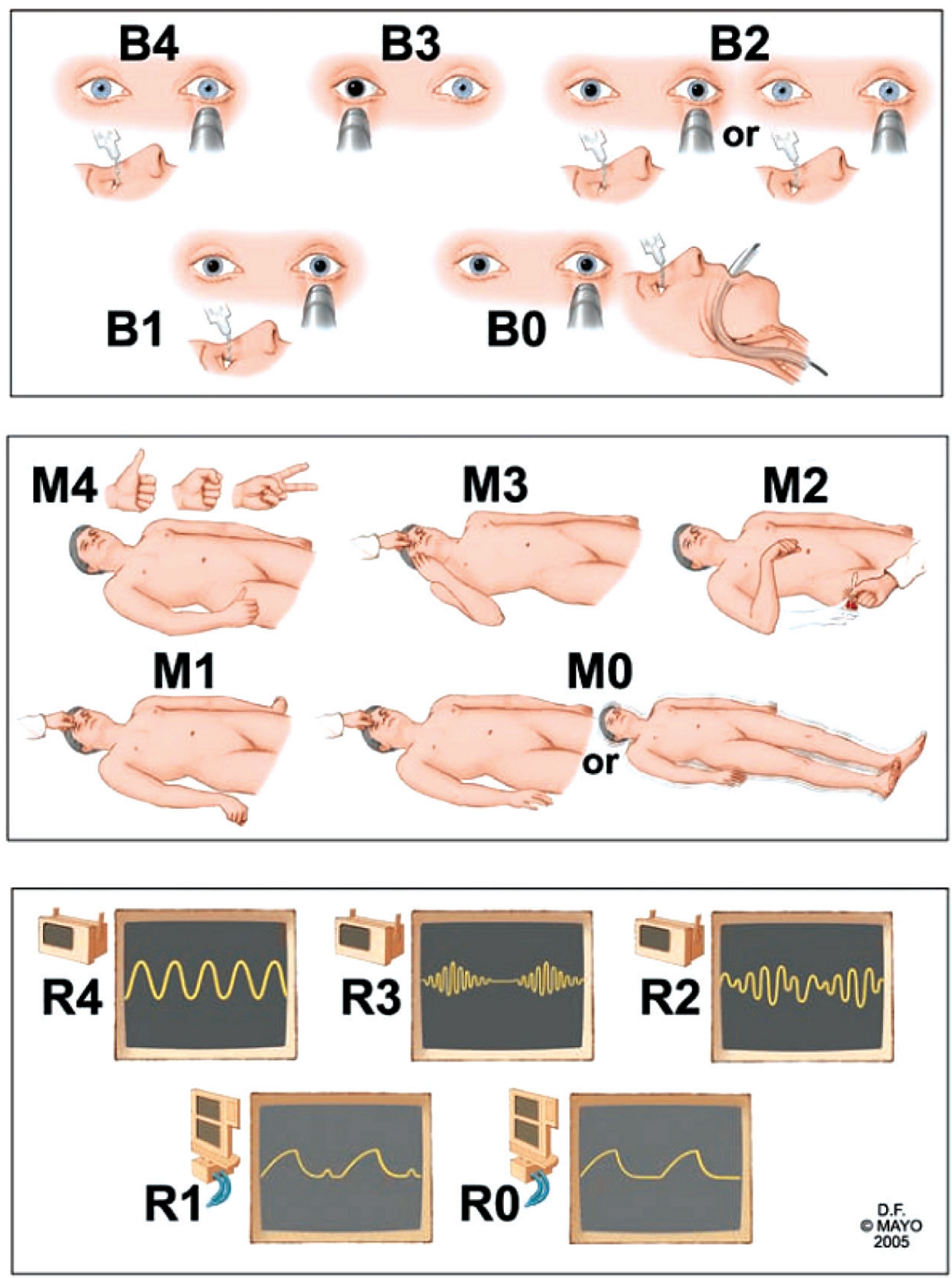

Gambar 1. Komponen penilaian pada FOUR score 


\section{Komponen penilaian pada FOUR score}

Penilaian motor dan respons mata pada FOUR score mirip dengan GCS, meskipun dengan beberapa pengecualian Pada FOUR score, respon motorik didapat terutama dari ekstremitas atas. Komponen motorik juga mengkombinasikan respons dekortikasi dan withdrawal. Pemeriksaan terhadap posisi tangan telah divalidasi sebelumnya dan dianggap reliabel untuk mendeteksi perubahan kesadaran sangat minimal. ${ }^{13-15}$ Pemeriksaan refleks batang otak dapat membantu dalam penilaian kedalaman koma yang lebih lengkap dan akurat. Pemeriksaan fungsi batang otak, seperti refleks cahaya pupil, refleks kornea, dan refleks batuk dapat menilai fungsi mesensefalon, pons, medula oblongata, dan saraf okulomotor. Refleks batuk hampir selalu menghilang bila refleks pupil dan kornea telah menghilang. ${ }^{13}$

Pola napas Cheyne-Stokes dan ireguler dapat mencerminkan adanya disfungsi bihemisfer atau batang otak bagian bawah yang mengendalikan pernapasan, dan berhubungan dengan prognosis buruk. Pada pasien yang terintubasi, jumlah frekuensi napas yang melebihi frekuensi yang diberikan oleh mesin menggambarkan masih adanya fungsi pusat pernapasan atau usaha napas. Bila semua komponen menghasilkan nilai 0 , dapat disimpulkan telah terjadi mati batang otak. ${ }^{13}$

\section{FOUR score vs GCS: kesesuaian, validi- tas, dan reliabilitas}

Berbagai penelitian yang telah dilakukan selama ini menunjukkan adanya kesesuaian total penilaian yang dilakukan oleh perawat, residen, ataupun dokter lain untuk FOUR score maupun GCS. ${ }^{16-19}$ Satu penelitian membuktikan tidak adanya perbedaan antara nilai total antara perawat, residen, atau dokter, baik dalam penggunaan FOUR score $(\mathrm{p}=0,777)$, ataupun GCS ( $\mathrm{p}=0,125) .{ }^{16}$ Reliabilitas FOUR score dan GCS dinilai cukup baik, baik pada kelompok yang belum ataupun telah terlatih. ${ }^{11}$ Reliabilitas yang didapat untuk FOUR score dan GCS dinilai sangat baik dengan angka kesesuaian masing-masing adalah 0,82 dan $0,86 .{ }^{10}$ Penelitian lain mendapatkan kesesuaian pada penggunaan FOUR score mencapai 0,882 dan pada GCS 0,862, dengan koefisien korelasi intrakelas berturut-turut 0,975 dan $0,964 .{ }^{16}$ Reliabilitas antar pemeriksa juga menunjukkan hasil yang sangat baik untuk FOUR score dan juga GCS, dengan korelasi intrakelas berada dalam rentang 0,90-0,99. ${ }^{13}$

Kesesuaian juga dinilai baik di antara dokter, seperti hasil yang didapat pada satu penelitian yang menunjukkan reliabilitas keseluruhan penilai pada FOUR score $\left(\kappa_{\text {FOUR }} 0.963 ; 0.890 ; 0.845\right)$ lebih baik daripada modifikasi GCS $\left(\kappa_{\mathrm{GCS}} 0.851 ; 0.740\right.$; 0.700). ${ }^{17}$ Kesesuaian terbaik didapat di antara residen neurologi, sedangkan yang terendah adalah di antara perawat neurologi. ${ }^{5}$ Dalam penilaian kesesuaian antar perawat berpengalaman, studi lain menunjukkan angka kappa yang lebih tinggi pada FOUR score $(0,92)$ dibandingkan dengan GCS $(0,86) .{ }^{20}$ Sensitivitas dan spesifitas FOUR score dianggap maksimal pada nilai ambang batas 9 (Sn 75\%, Sp 76\%), dan pada nilai 7 untuk GCS (Sn 80\%, Sp 80\%). ${ }^{21}$

\section{Kesimpulan}

Dari berbagai penelitian yang telah dilakukan, FOUR score terbukti memiliki validitas, reliabilitas, dan kesesuaian yang cukup baik. Empat komponen yang terkandung dalam FOUR score memberikan detil informasi dari pemeriksaan neurologis seperti refleks batang otak dan pergerakan mata. FOUR score lebih sederhana dan memberikan informasi yang lebih baik, terutama pada pasien-pasien yang terintubasi, sehingga direkomendasikan untuk digunakan di ruang perawatan intensif.

\section{Daftar pustaka}

1. Bordini AL, Luiz TF, Fernandes M, Arruda WA, Teive HA. Coma scales: a historical review. Arq Neuropsiquiatr 2010;68:930-7.

2. Iyer VN, Mandrekar JN, Danielson RD, Zubkov AY, Elmer JL, Wijdicks EFM. Validity of the FOUR score coma scale in the medical intensive care unit. Mayo Clin Proc 2009;84:694-701.

3. Farouq MO. Looking for an ideal coma scale: It is time to replace GCS. Bangladesh Crit Care J 2014;2:1-3.

4. Mansour OY, Megahed MM, Abd Elghany EHS. Acute ischemic stroke prognostication, comparison between Glasgow Coma Score, NIHS Scale and Full Outline of UnResponsiveness Score in intensive care unit. Alex J Med. 2015;51:247-53.

5. Heather NL.Derraik JG, Beca J, Hofman PL, Dansey 
R, Cutfield WS, dkk. Glasgow Coma Scale and outcomes after Structural Traumatic Head Injury in early childhood. PloS One 2013;8:e82245-51.

6. Reith FC, Van den Brande R, Synnot A, Gruen R, Maas AI. The reliability of the Glasgow Coma Scale: a systematic review. Intensive Care Med 2016;42:3-15.

7. Mahdian M, Fazel MR, Fakharian E, Akbari H, Mahdian S. Cerebral state index versus Glasgow coma scale as a predictor for in-hospital mortality in brain-injured patients. Chinese J Trauma 2014;17:220-4.

8. Holmes JF, Palchak MJ, MacFarlane T, Kuppermann N. Performance of the pediatric Glasgow Coma Scale in children with blunt head trauma. Acad Emerg Med 2005;12:814-9.

9. Kirkham FJ, Newtton CR, Whitehouse W. Pediatric coma scales. Dev Med Child Neurol 2008;50:267-74.

10. Wijdicks EFM, Bamlet WR, Maramattom BV, Manno EM, McClelland RL. Validation of a new coma scale: The FOUR score. Ann Neurol 2005;58:585-93.

11. Khajeh A, Fayyazi A, Miri-Aliabad G, Askari K, Noori N, Khajeh K. Comparison between the ability of Glasgow Coma Scale and Full Outline of Unresponsiveness Score to predict the mortality and discharge rate of pediatric intensive care unit patients. Iran J Pediatr 2014;24: 603-8.

12. Sahin AS, Sahin M, Öztürk NK, Kizilates E, Karsli B. Comparision Of GCS And FOUR Scores used in the evaluation of neurological status in intensive care units. J Contemp Med 2015;5:167-72.

13. Akavipat P. Endorsement of the FOUR score for consciousness assessment in neurosurgical patients. Neurol Med Chir 2009;49:565-71.

14. Eken C, Kartal M, Bacanli A, Eray O. Comparison of the Full Outline of Unresponsiveness score coma scale and the Glasgow Coma Scale in an emergency setting population. Eur J Emerg Med 2009;16:29-36.

15. Chen B, Grothe C, Schaller K. Validation of a new neurological score (FOUR Score) in the assessment of neurosurgical patients with severely impaired consciousness. Acta Neurochir 2013;155:2133-9.

16. Stead LG, Wijdicks EFM, Bhagra A, Kashyap R, Bellolio MF, Nash DL, dkk. Validation of a new coma scale, the FOUR score, in the emergency department. Neurocrit Care 2009;10:50-4.

17. Dewi R, Mangunatmadja I, Yuniar I. Perbandingan FOUR Score dengan GCS dalam menentukan prognostik pasien rawat inap di unit perawatan intensif anak. Sari Pediatri 2011;13:215-25.

18. Murthy TVSD. A new score to validate coma in emergency department - FOUR score. IJNT 2009;6:5962.

19. Wijdicks EF. Clinical scales for comatose patients: the Glasgow Coma Scale in historical context and the new FOUR score. Rev Neurol Dis 2006;3:109-17.

20. Wolf CA, Wijdicks EFM, Bamlet WR, McClelland RL. Further validation of the FOUR score coma scale by intensive care nurses. Mayo Clin Proc 2007;82:435-8.

21. Cohen J. Interrater reliability and predictive validity of the FOUR score coma scale in a pediatric population. J Neuroscience Nurs 2009;41:261-7. 